\title{
ESQUIZOFRENIA HEBEFRÊNICA: PSICOSE NA INFÂNCIA E ADOLESCÊNCIA ${ }^{\star}$
}

\author{
Hugo Leonardo Rodrigues Soares $\star \star$

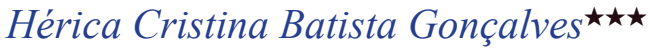 \\ Jairo Werner Junior ${ }^{\star \star \star \star}$
}

\section{Palavras-chaves: Esquizofrenia; Psiquiatria Infantil; Psicose}

Introdução: a esquizofrenia com início na infância geralmente se refere ao desenvolvimento de alucinações, delírios, e desorganização da linguagem em crianças e adolescentes com menos de 15 anos de idade. É um transtorno incomum, e o início na pré-puberdade é extremamente raro. Os critérios diagnósticos de esquizofrenia são semelhantes exceto pela idade de início - infância, adolescência ou idade adulta. O diagnóstico exige a presença de alucinações incongruentes do humor, delírios e linguagem desorganizada, associados a deterioração do funcionamento. A esquizofrenia é definida na criança como no adulto, à base de sintomas psicóticos, déficit da função adaptativa e duração de no mínimo seis meses. A prevalência da esquizofrenia com início na infância é relatada como $2 \%$ da prevalência da esquizofrenia com início na idade adulta. Outros estudos têm indicado que a prevalência da esquizofrenia na infância é menor que 1 por 1000 habitantes e que a prevalência da esquizofrenia em crianças menores de 15 anos é 0,14 por 1000 habitantes. A esquizofrenia hebefrênica é uma forma de esquizofrenia caracterizada pela presença proeminente de uma perturbação dos afetos; as idéias delirantes e as alucinações são fugazes e fragmentárias, o comportamento é irresponsável e imprevisível; existem freqüentemente maneirismos. O afeto é superficial e inapropriado. O pensamento é desorganizado e o discurso incoerente. Há uma tendência ao isolamento social. Geralmente o prognóstico é desfavorável devido ao rápido desenvolvimento de sintomas "negativos", particularmente um embotamento do afeto e perda da volição. A hebefrenia deveria normalmente

^ Trabalho apresentado na 29a Semana Científica da Faculdade de Medicina da UFF, realizada em 30 de novembro e 1 de dezembro de 2006, no Hospital Universitário Antônio Pedro, Niterói, Rio de Janeiro.

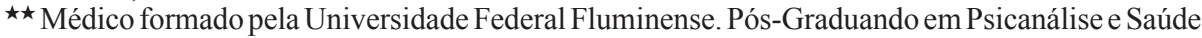
Mental pela UERJ. Ex-monitor das disciplinas de Neuropsiquiatria Infantil e Desenvolvimento Infantil. Especialista em Dependência Química pela UNIFESP/EPM. Pòs-Graduado (lato sensu) Políticas, Instituições e Saúde Mental e Vigilância Sanitária. Fiocruz/Ensp.

E-mail|: hlsoares@brfree.com.br

$\star \star \star$ Psicóloga, residente em Saúde Mental do Instituto Municipal Philippe Pinel.

E-mail: hericacris@yahoo.com.br

$\star \star \star \star$ Orientador e professor adjunto IV, responsável pela área de Psiquiatria da Infância e Adolescência da Faculdade de Medicina (Departamento Materno Infantil) do Centro de Ciências Médicas da UFF. Médico e Doutor em Saúde Mental -UNICAMP e Mestre em Educação - UFF. Endereço: Departamento Materno-Infantil - Faculdade de Medicina - Hospital Universitário Antônio Pedro (HUAP) - Rua Marquês do Paraná, 303, Centro, Niterói - RJ, CEP 24303-900.

E-mail: jairowerner@globo.com 
ser somente diagnosticada em adolescentes e em adultos jovens. A esquizofrenia quando aparece na infância, é um quadro grave, com mau prognóstico, na maioria dos casos. Incide numa personalidade que ainda não está completamente desenvolvida e bloqueia o processo do desenvolvimento dessa personalidade. Por isto, considera-se que a gravidade é menor quanto mais velha está a criança, pelas defesas que já têm estruturadas. Objetivos: Apresentar uma experiência interdisciplinar no campo da Saúde Mental Infantil, especificamente na esquizofrenia hebefrênica, partindo do princípio "interação social como constitutiva dos processos psíquicos individuais", e garantindo a perspectiva histórico-cultural A atuação multidisciplinar e cooperação inter-institucional são essenciais para uma melhor abordagem da patologia em questão, sendo de vital importância para um melhor prognóstico da doença. Metodologia: Apresentar o relato de um caso de esquizofrenia hebefrênica, em atendimento no Projeto Psiquiatria Infantil Sem Paredes da UFF desde 01/10/2004, com a abordagem interdisciplinar e interinstitucional. Resultados e Conclusões: $O$ tratamento atual para a esquizofrenia com início na infância e semelhante ao empregado na esquizofrenia com início na idade adulta. Ele deve incluir uma abordagem de multimodalidade. A terapia envolve não apenas a medicação, mas também abordagens individuais, familiares , e educacionais. Através da interdisciplinaridade pode-se observar a eficiência da terapêutica, bem como a possibilidade de atenção integrada, e a re-inserção social do paciente. Pode-se concluir que a abordagem utilizada visa contribuir para a melhoria na qualidade de vida e dos processos psíquicos e sociais dos indivíduos incluídos nessa categoria, representando as possibilidades promissoras do enfoque multidiciplinar e inter-institucional na Saúde Mental Infantil. 